\title{
Hydrogenation of Styrene Oxide to 2-Phenylethanol over Nanocrystalline Ni Prepared by Ethylene Glycol Reduction Method
}

\author{
Sunil K. Kanojiya, ${ }^{1}$ G. Shukla, ${ }^{1}$ S. Sharma, ${ }^{1}$ R. Dwivedi, ${ }^{2}$ P. Sharma, ${ }^{2}$ \\ R. Prasad, ${ }^{2}$ M. Satalkar, ${ }^{3}$ and S. N. Kane ${ }^{3}$ \\ ${ }^{1}$ IPCA Laboratories Ltd., Indore 452003, India \\ ${ }^{2}$ School of Chemical Sciences, DA University, Indore 452001, India \\ ${ }^{3}$ Magnetic Materials Laboratory, School of Physics, DA University, Indore 452001, India
}

Correspondence should be addressed to R. Prasad; rjndr.prsd3@gmail.com

Received 14 February 2014; Accepted 20 May 2014; Published 17 July 2014

Academic Editor: Moshe Sheintuch

Copyright (C) 2014 Sunil K. Kanojiya et al. This is an open access article distributed under the Creative Commons Attribution License, which permits unrestricted use, distribution, and reproduction in any medium, provided the original work is properly cited.

\begin{abstract}
Nanocrystalline nickel prepared by glycol reduction method and characterized by XRD and magnetic measurements has been used as a catalyst for hydrogenation of styrene oxide to 2-phenylethanol. Effect of process variables such as particle size of the catalyst, temperature, and pressure have been optimized to achieve a maximum conversion of $98 \%$ of styrene oxide with $99 \%$ selectivity towards 2-phenylethanol. The structure of the transition state has been computed employing density functional theory and using Gaussian 09 suite. The enthalpy of reaction $(\Delta H)$ and activation energy $\left(E_{a}\right)$ are calculated to be $85.3 \mathrm{kcal} \cdot \mathrm{mol}^{-1}$ and $123.03 \mathrm{kcal} \cdot \mathrm{mol}^{-1}$, respectively. A tentative mechanism for the reaction is proposed according to which atomized hydrogen and styrene oxide react together over the catalyst surface to produce 2-phenylethanol.
\end{abstract}

\section{Introduction}

2-Phenylethanol (2-PEA) having smell of rose petals is a material of commerce and finds applications as fragrance chemical [1-4] antimicrobial and antifungicidal agent $[5,6]$. Many perfumes, cosmetics, and deodorant formulations are based on this compound. Its esters such as phenyl ethyl acetate are equally important in perfumery industries. In conventional process 2 -phenylethanol is produced by reacting benzene with ethylene oxide and using anhydrous $\mathrm{AlCl}_{3}$ as a catalyst [7-9]. The process has the disadvantages of using ethylene oxide, which is an explosive chemical and requires special care and license. $\mathrm{AlCl}_{3}$ can be used only once and creates disposal problem. The process leads to the formation of side products such as biphenyl which results into poor selectivity towards 2-PEA.

Conventional catalyst used for many hydrogenation reactions is Raney nickel (particle size of about $25 \mathrm{~nm}$ ) which is prepared by dissolving $\mathrm{Ni}-\mathrm{Al}$ alloy in $\mathrm{NaOH}$ and removing the sodium aluminate by repeated washing with water which is time consuming [10-13]. In the present work nanonickel is prepared by glycol reduction process which is simple and takes much less time compared to that required for Raney nickel preparation. Also particle size can be reduced to as low as $5 \mathrm{~nm}$.

Liquid phase [14-20] as well as vapour phase [21, 22] processes have been used to convert styrene oxide (SO) into 2-PEA. Liquid phase reactions are performed under pressure using either pure metal $(\mathrm{Ni}, \mathrm{Pd}, \mathrm{Pt})$ or supported metals on carriers like Cao, $\mathrm{SiO}_{2}$, and $\mathrm{MgO}$.

There are reports on the production of 2-phenylethanol by reduction of styrene oxide with hydrogen in slurry phase 5 using Pd supported on carbon [4-6]. Recently, there have been few reports on the hydrogenation of styrene oxide employing alumina supported Pt catalyst [7]. In these processes costly metals like Pd and Pt are used as catalyst. There is a cursory report on reduction of styrene oxide to 2-PEA by hydrogen over transition metals supported over 


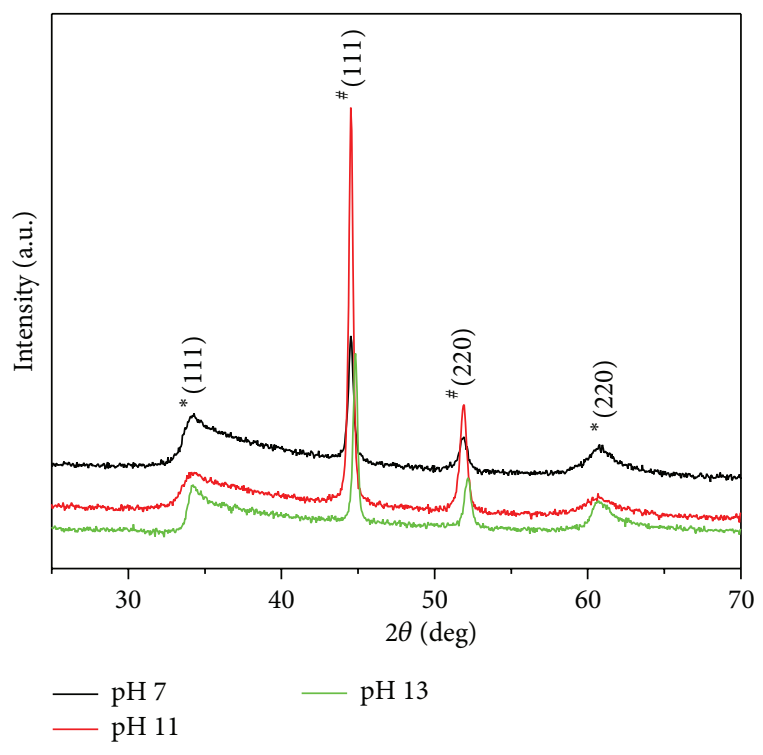

FIGURE 1: XRD pattern of nano Ni catalyst. $*=\mathrm{NiO}$, \# = Ni.

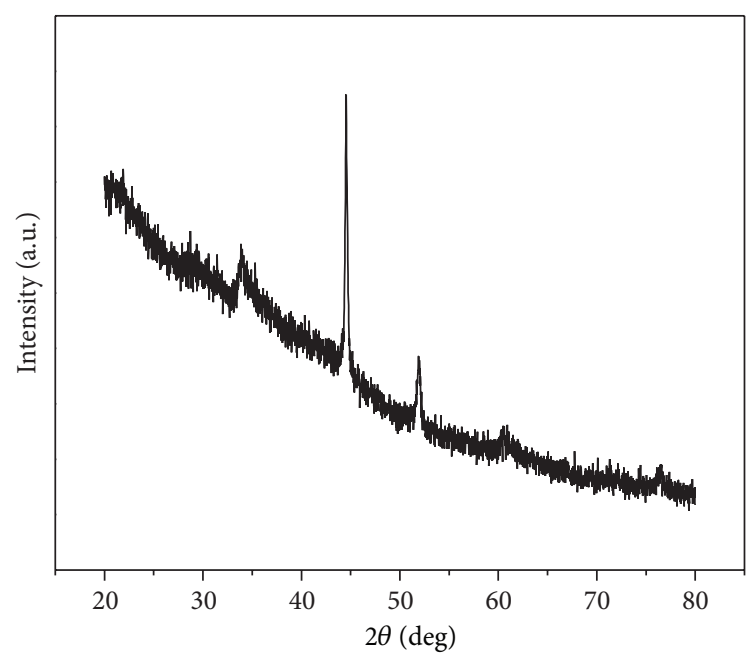

FIGURE 2: XRD pattern of spent catalyst.

carbon [8]. To the best of our knowledge, there seems to be no report on the hydrogenation of styrene oxide using nanonickel as catalyst prepared by glycol reduction process. In view of this the present problem of reduction of styrene oxide with hydrogen over nanonickel was undertaken with the objectives of (1) synthesizing the nanonickel by glycol reduction process (2) to characterize it by spectroscopic and surface area measurement process (3) to evaluate its performance as catalyst for hydrogenation of styrene oxide to 2-phenylethanol and (4) to predict a tentative mechanism of the process.

\section{Experimental}

2.1. Preparation of Catalyst and Its Characterization. In a three necked flask fitted with a thermometer and a water

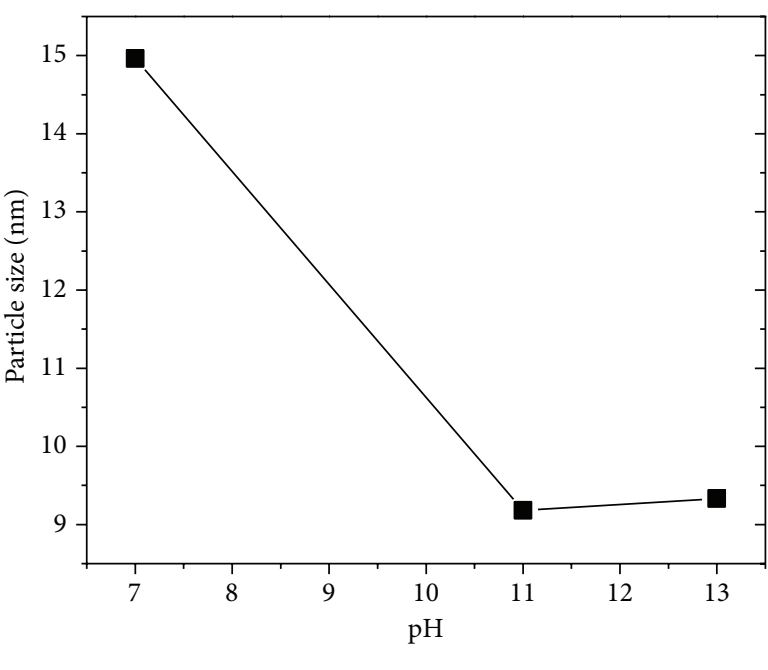

B

Figure 3: Effect of $\mathrm{pH}$ on particle size of catalyst.

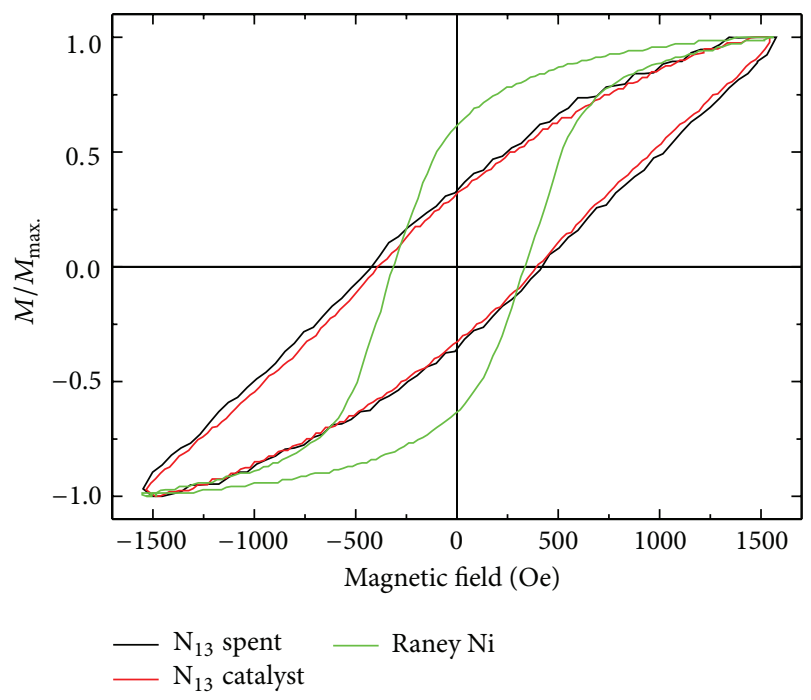

Figure 4: (a) Raney nickel (b), $\mathrm{N}_{13}$ catalyst, and (c) $\mathrm{N}_{13}$ spent catalyst.

condenser a $2 \%$ solution of anhydrous nickel acetate in ethylene glycol was taken, $\mathrm{pH}$ adjusted with $\mathrm{NaOH}$ solution, and refluxed till whole of the nickel acetate was converted to $\mathrm{Ni}$ indicated by change of color from green to brown.

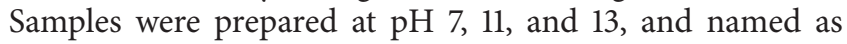
$\mathrm{N}_{7}, \mathrm{~N}_{11}$, and $\mathrm{N}_{13}$. The anhydrous nickel acetate was prepared simply by drying laboratory grade nickel acetate in oven at $105^{\circ} \mathrm{C}$ for few hours till a constant weight was achieved. Small amount of the product was taken out for characterization. The catalyst was always kept covered with ethylene glycol and taken out only when needed for characterization or for application as a catalyst. X-ray diffraction "XRD" $(\theta-2 \theta)$ configuration patterns of the studied sample were obtained by Bruker $\mathrm{D} 8 \mathrm{Advance}$ diffractometer, with $\mathrm{Cu}-\mathrm{K}_{\alpha}$ radiation $(\lambda=0.154 \mathrm{~nm})$. Room temperature magnetic properties of the studied samples were measured using a digital hysteresis 


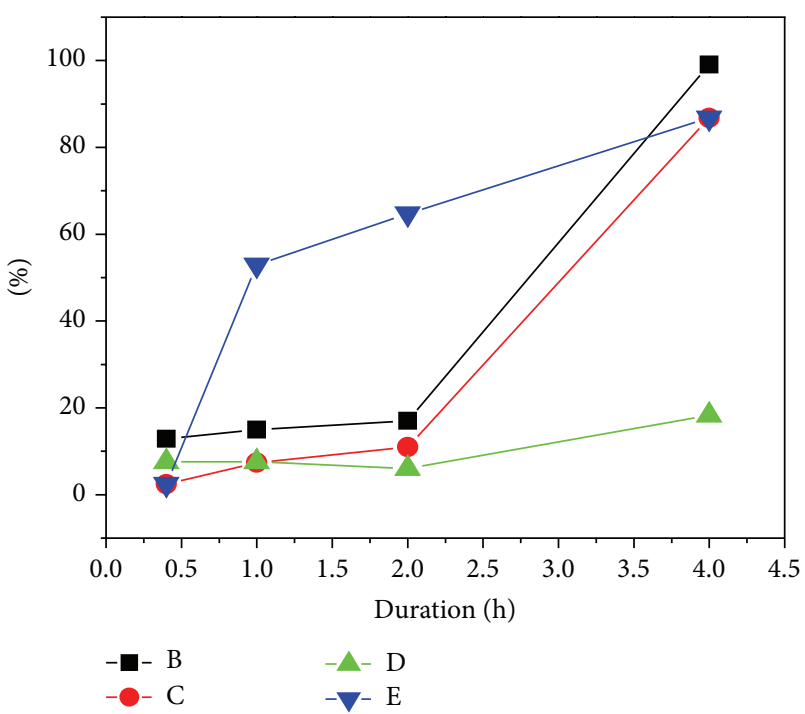

FIGURE 5: Effect of duration of reaction. $\mathrm{B}=$ conversion, $\mathrm{C}=2$-PEA yield, $\mathrm{D}=$ others, and $\mathrm{E}=2$-PEA selectivity.

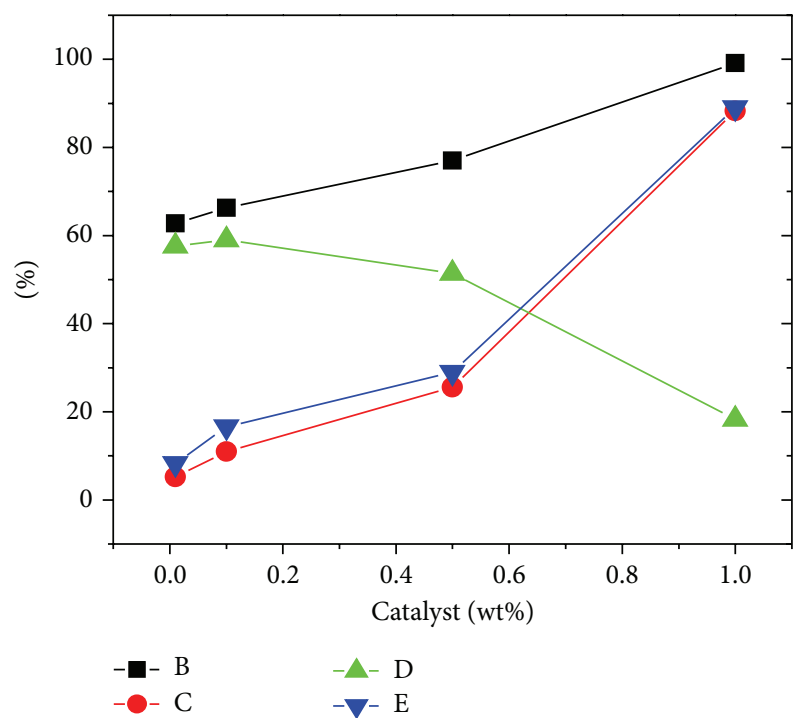

FIGURE 6: Effect of catalyst loading on the performance of the catalyst. $\mathrm{B}=$ conversion, $\mathrm{C}=2$-PEA yield, $\mathrm{D}=$ others, and $\mathrm{E}=2$ PEA selectivity.

loop tracer employing conventional induction technique with a maximum field of \pm 1600 Oe.

2.2. Catalyst Evaluation. Catalytic performance of the prepared catalyst for reduction of styrene oxide was evaluated in a 2lt stainless steel pressure reactor supplied by Amar Engineering Mumbai. The reactor was fitted with a mechanical stirrer and pressure gauze. Heating was performed by circulating thermal fluid to the coil fitted internally to the reactor. In a typical rum $50 \mathrm{~g}$ of styrene oxide in $500 \mathrm{~mL}$ of methanol and $2.5 \mathrm{~g}$ of catalyst was charged to the reactor and heated to $110^{\circ} \mathrm{C}$. The reactor was pressurized through a hydrogen gas cylinder to the desired pressure $\left(40-100 \mathrm{~kg} \cdot \mathrm{cm}^{-2}\right)$.

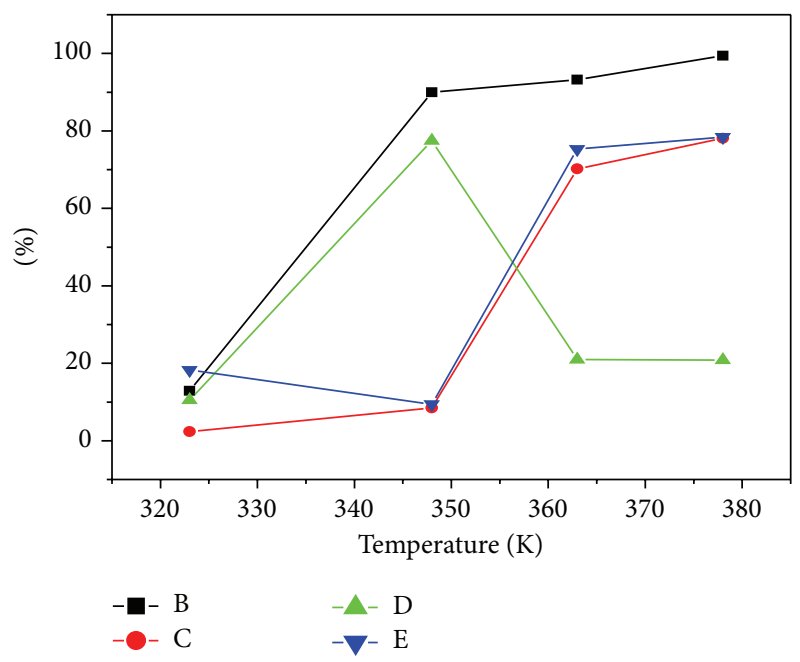

FIGURE 7: Effect of temperature on performance of catalyst. $\mathrm{B}=$ conversion, $\mathrm{C}=2$ - $\mathrm{PEA}$ yield, $\mathrm{D}=$ others, and $\mathrm{E}=2$-PEA selectivity.

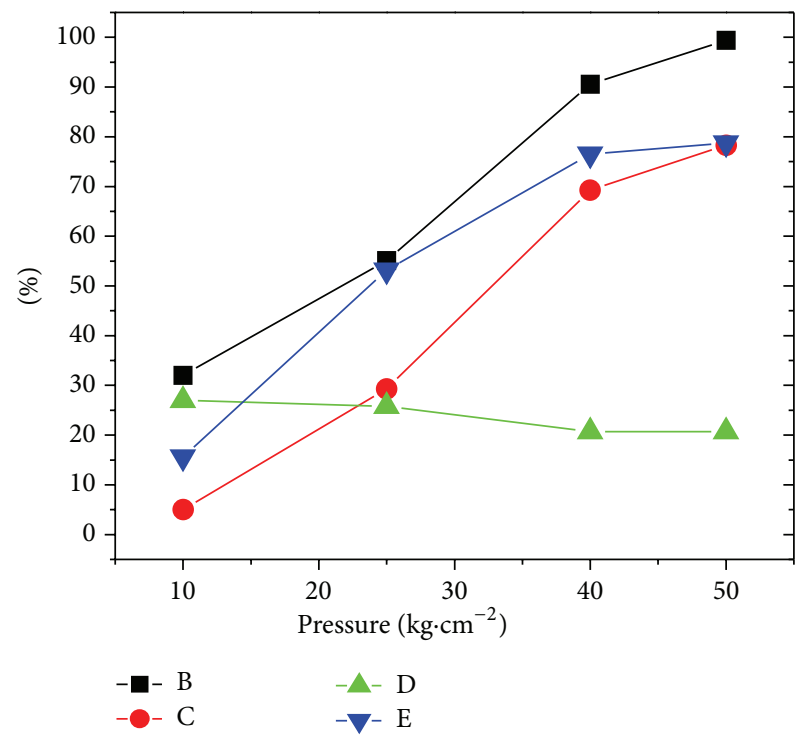

FIGURE 8: Effect of pressure on catalyst performance. Temp. $=378 \mathrm{~K}$, catalyst loading $=1 \%$, duration $=4$ hrs. $\mathrm{B}=$ conversion, $\mathrm{C}=\mathrm{PEA}$ yield, $\mathrm{D}=$ Others, and $\mathrm{E}=$ Selectivity.

The gas pressure decreases slowly with time and finally becomes constant at completion of the reaction. After completion of the reaction the reactor is opened, catalyst is filtered, solvent is distilled, and product mixture is analyzed over a Chemito GLC machine using SE-30 column and FID detector.

\section{Results and Discussion}

3.1. Catalyst Characterization. The XRD patterns of the catalyst prepared at different $\mathrm{pH}$ are reproduced in Figure 1. The particle size was calculated from the 111 peak of the powder employing Scherer's formula [23]. Assignment of XRD peaks were made by comparing the reported pattern 


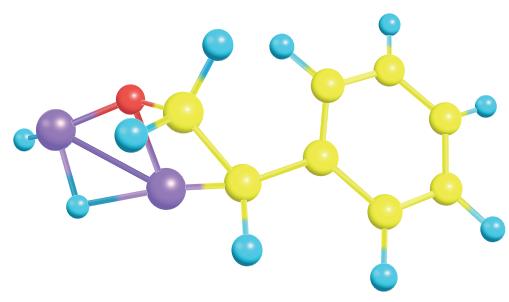

(a)

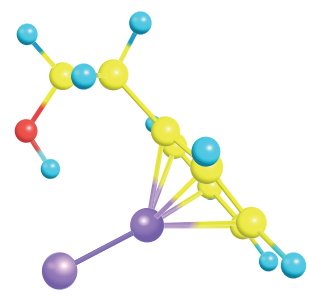

(b)

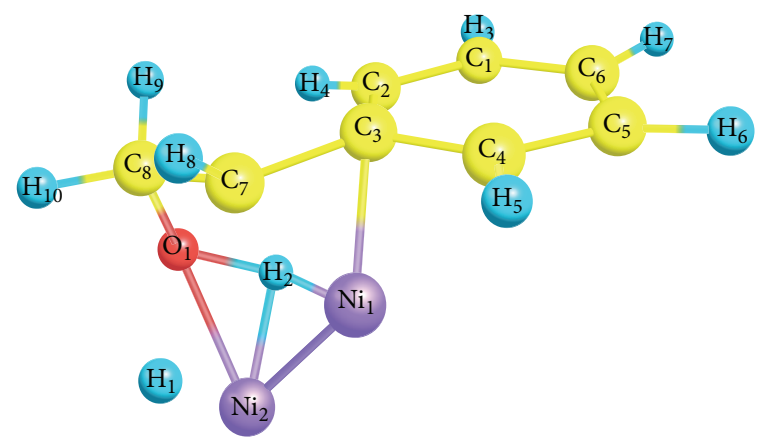

(c)

Figure 9: Structure of (a) reactant model, (b) product model, and (c) TS for hydrogenation of styrene oxide to 2-phenylethanol.

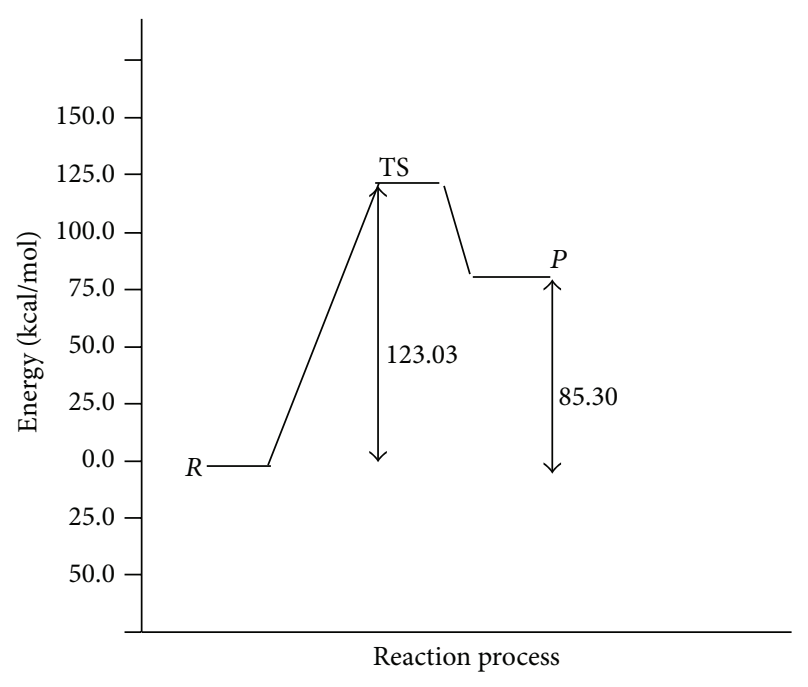

FIGURE 10: Potential energy diagram for hydrogenation of styrene oxide over Ni catalyst.

of Ni by Garcia-Cerda et al. [24] and are shown over the observed peaks. The sample is a mixture of $\mathrm{Ni}$ and $\mathrm{NiO}$. The formation of $\mathrm{NiO}$ seems to be due to air exposure of the catalyst during XRD measurement.

The pattern matches well with the reported pattern. The XRD pattern of the spent catalyst is shown in Figure 2. The pattern matches well with the initial catalyst employing that there is no change in the crystal structure of the catalyst after use. The variation of particle size with $\mathrm{pH}$ for the fresh catalysts is shown in Figure 3. Increasing $\mathrm{pH}$ reduced the particle size. However, the crystal size of the spent $\mathrm{N}_{13}$ catalyst increased to $11.73 \mathrm{~nm}$ as compared to $9.33 \mathrm{~nm}$ for fresh $\mathrm{N}_{13}$ catalyst.

Magnetic measurements of Raney $\mathrm{Ni}$ as well as spent and fresh $\mathrm{Ni}$ nanoparticles prepared at $\mathrm{pH} 13$ are depicted in Figure 4. Analysis of magnetic measurements shows that Raney Ni has coercivity of $330 \mathrm{Oe}$, whereas that of bulk Ni is 0.7 Oe [25]. Observed change in the coercivity can be attributed to the different grain diameters in Raney $\mathrm{Ni}$ and in bulk Ni. Magnetic measurements done on spent and fresh Ninanoparticles reveal that they are highly anisotropic (whereas Raney Ni is not that anisotropic), as can be seen in hysteresis measurements (Figure 4). As the applied magnetic field is less than saturating field for the case of prepared Ni nanoparticles the samples could not be saturated, so the coactivity could not be estimated. An inspection of the hysteresis loops for nano Ni suggests that its coercivity will be higher than that of Raney Ni. This further suggests smaller size of the prepared nanoparticles compared to bulk and Raney Ni.

3.2. Effect of Duration of Reaction. Effect of duration of reaction was studied to have an idea of completion of the reaction. Results are shown graphically in Figure 5. Increasing duration of reaction increased conversion of styrene oxide as well as yield and selectivity of 2-PEA. It was found that duration of $4 \mathrm{hrs}$ was enough for the completion of the reaction. No hydrogen was consumed after 4 hrs. Duration of subsequent experiments was therefore kept at $4 \mathrm{hrs}$.

3.3. Effect of Catalyst Loading. Effect of catalyst loading was studied with the objective of finding optimum catalyst/styrene oxide ratio. The results are shown graphically in Figure 6. A 99\% conversion was achieved at a catalyst loading of $1 \%$. Yield as well as selectivity of PEA increased with increase in catalyst loading. It is interesting to note that with increased yield of 2-PEA, conversion to byproducts decreased.

3.4. Effect of Temperature on Reaction. Effect of temperature on the performance of the catalyst prepared at $\mathrm{pH} 13$ was studied at pressure of $50 \mathrm{~kg} \cdot \mathrm{cm}^{-2}$ and catalyst loading of $1 \%$. The results are presented in Figure 7. The conversion rises sharply with increase in temperature. A maximum conversion of $99.42 \%$ with yield of $78 \%$ of 2 -PEA was reached at a temperature of $378 \mathrm{~K}$. At moderate temperature of $348 \mathrm{~K}$ the conversion to byproduct was high.

3.5. Effect of Pressure. Effect of pressure on the performance of the catalyst was studied in the range $0-50 \mathrm{~kg} \cdot \mathrm{cm}^{-2}$ and 


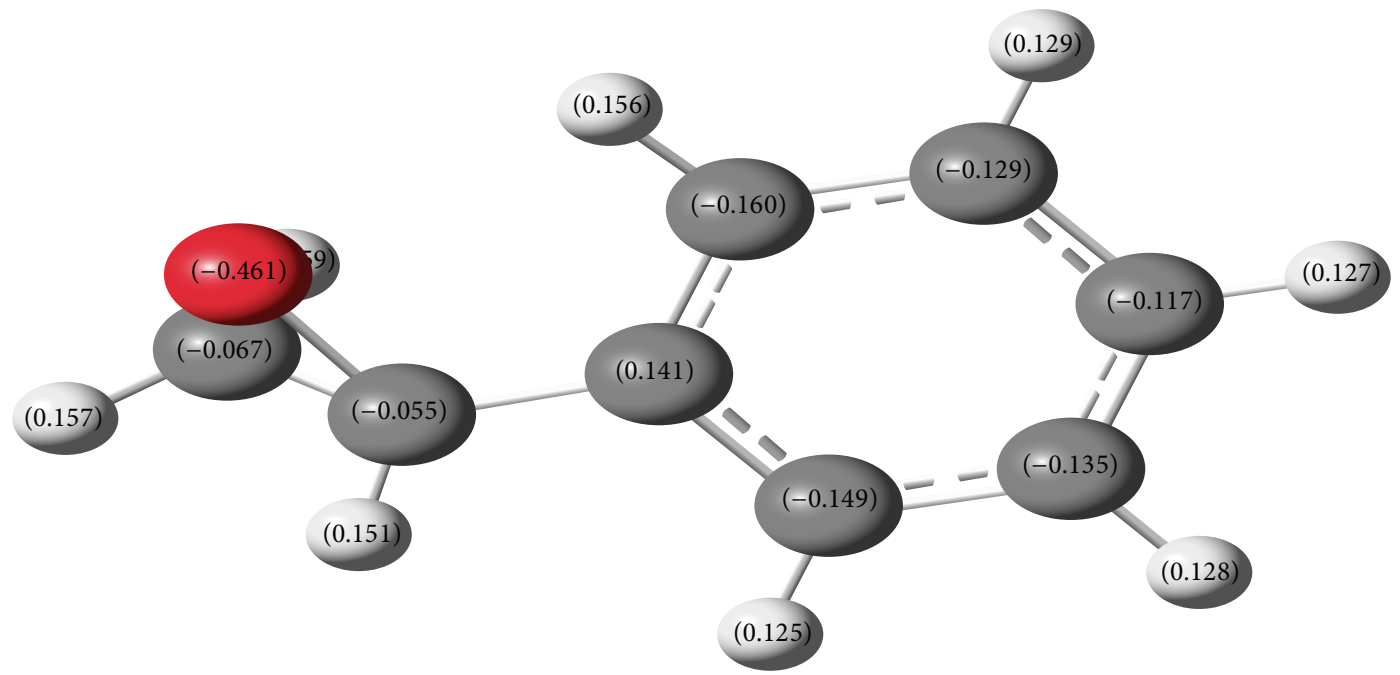

FIGURE 11: Geometry of styrene oxide showing atomic charges (Coulomb).

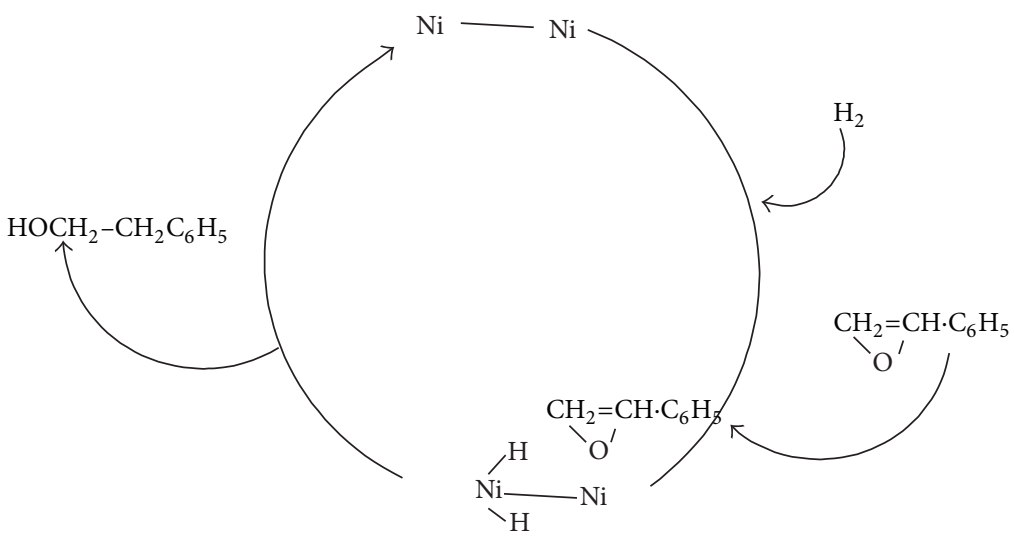

Figure 12: Model of the catalytic cycle for hydrogenation of styrene oxide over Ni catalyst.

results are presented in Figure 8. Conversion of styrene oxide, as well as yield and selectivity of 2-PEA, increased with pressure. At the same time yield of byproducts decreased with pressure. A maximum conversion of $99.42 \%$ of styrene and $78.3 \%$ yield of 2 -PEA with selectivity of $78.8 \%$ could be achieved at a pressure of $50 \mathrm{~kg} \cdot \mathrm{cm}^{-2}$.

3.6. Mechanism of the Reaction. Most of mechanisms for hydrogenation of alkenes are based on the assumption that hydrogen is first atomized on the catalyst surface which is subsequently added to the double bond producing a saturated hydrocarbon. These descriptions are qualitative in general and there is no quantitative proof of the mechanism. In order to get a clue to the adsorption of hydrogen on the $\mathrm{Ni}$ surface and subsequent atomization we performed a density functional theory (DFT) calculation of the adsorption of hydrogen on Ni employing Gaussian 09 suite. We used Beck's three parameter hybrid method with the Lee, Yang, and Parr (B3LYP) exchange correlation functional to perform these calculations. Geometries were optimized using standard 6$31 \mathrm{G}^{*}$ basis set. Heat of adsorption was calculated using the following formula.

$E_{\text {ads }}=E_{\text {(adsorbate - subtrate) }}-\left(E_{\text {adsorbate }}+E_{\text {substrate }}\right)$ and was calculated to be $-77.59 \mathrm{kcal} \cdot \mathrm{mol}^{-1}$.

The optimized geometries of reactant model, product model, and transition state are shown in Figure 9 and the related potential energy surface is shown in Figure 10.

The atomic charges (coulomb) in the reactant models are, respectively, $\mathrm{Ni}_{1}=0.445, \mathrm{Ni}_{2}=0.332, \mathrm{O}_{1}=-0.672$, $\mathrm{H}_{1}=-0.082, \mathrm{H}_{2}=-0.112, \mathrm{H}_{3}=0.126, \mathrm{H}_{4}=0.156, \mathrm{H}_{5}=$ $0.122, \mathrm{H}_{6}=0.125, \mathrm{H}_{7}=0.124, \mathrm{H}_{8}=0.143, \mathrm{H}_{9}=0.154, \mathrm{H}_{10}=$ $0.164, \mathrm{C}_{1}=-0.127, \mathrm{C}_{2}=-0.164, \mathrm{C}_{3}=0.144, \mathrm{C}_{4}=-0.167$, $\mathrm{C}_{5}=-0.124, \mathrm{C}_{6}=-0.125, \mathrm{C}_{7}=-0.484$, and $\mathrm{C}_{8}=0.021$. Free nickel atom possesses no charge. Opposite charges on nickel atoms and negative charges on $\mathrm{O}_{1}, \mathrm{H}_{1}$, and $\mathrm{H}_{2}$ suggest electrostatic nature of adsorption. All carbon atoms accept $\mathrm{C}_{3}$ and $\mathrm{C}_{8}$ bears negative charge. This can also be ascribed to adsorption of SO. It is worth noting that in the reactant model, the epoxide bond is broken and new bonds are formed 
between $\mathrm{O}_{1}$ and $\mathrm{C}_{7}$ with $\mathrm{Ni}_{1}$ and $\mathrm{Ni}_{2}$. The adsorbed reactant model is therefore something like an intermediate. The charge distribution in styrene oxide (SO) is shown in Figure 11. Higher atomic charge on oxygen in adsorbed SO compared to that in free SO suggests transfer of charge from $\mathrm{Ni}$ atoms to Oxygen atom. The enthalpy difference and activation energy are, respectively, found to be 85.30 and $123.03 \mathrm{kcal} \cdot \mathrm{mol}^{-1}$. The catalytic cycle for the reaction is shown in Figure 12.

\section{Conflict of Interests}

The authors declare that there is no conflict of interests regarding the publication of this paper.

\section{References}

[1] K. Bauer, D. Garbe, and H. Surburg, Common Fragrance and Flavor Materials, Wiley-VCH, New York, NY, USA, 1990.

[2] E. T. Theimer, Theimer in Fragrance Chemistry, Academic Press, New York, NY, USA, 1982.

[3] B. D. Mookherjee and R. A. Wilson, Eds., Kirk-Othmer Encyclopedia of Chemical Technology, vol. 4, John Wiley \& Sons, New York, NY, USA, 4th edition, 1996.

[4] C. V. Rode, V. S. Kshirsagar, V. H. Rane, and R. V. Chaudhari, "Process for preparation of 2-phenyl ethanol," US Patent 6979753, 2005.

[5] J. J. Lucchini, N. Bonnaveiro, A. Cremieux, and F. Le Goffic, "Mechanism of bactericidal action of phenethyl alcohol in Escherichia coli," Current Microbiology, vol. 27, no. 5, pp. 295300, 1993.

[6] J. Corre, J. J. Lucchini, G. M. Mercier, and A. Cremieux, "Antibacterial activity of phenethyl alcohol and resulting membrane alterations," Research in Microbiology, vol. 141, no. 4, pp. 483-497, 1990.

[7] K. Bauer, D. Garbe, and H. Surburg, Common Fragrance and Flavour Materials, VCH Publishers, New York, NY, USA, 1990.

[8] H. S. Davis, "Manufacture of Aromatic alcohol," US patent 2125490A-1935.

[9] E. T. Theimer and N. J. Newark, "Synthetic production of alcohols," USP, vol. 2, Article ID 047396, 1933.

[10] A. A. Pavlic and H. Adkins, "Preparation of a Raney nickel catalyst," Journal of the American Chemical Society, vol. 68, no. 8, p. 1471, 1946.

[11] F. Montino, C. Monferrato, and L. Colombo, "Process for preparing finely particled $\mathrm{Ni}$ Powders having a spheroidal form," USP 3850612, 1974.

[12] N. H. Kwon, J. H. Lee, B. Roh et al., "Methods for preparing nanosized metal particles on C support," US Patent 8524420 B2, 2013.

[13] Z. Király, B. Veisz, Á. Mastalir, and G. Köfaragó, "Preparation of ultrafine palladium particles on cationic and anionic clays, mediated by oppositely charged surfactants: catalytic probes in hydrogenations," Langmuir, vol. 17, no. 17, pp. 5381-5387, 2001.

[14] C. A. Gibson and L. F. Theiling, "Hydrogenation of styrene oxide to 2-henylethanol," USP 4064186, 1977.

[15] C. V. Rode, M. M. Telkar, R. Jaganathan, and R. V. Chaudhari, "Reaction kinetics of the selective liquid phase hydrogenation of styrene oxide to $\beta$-phenethyl alcohol," Journal of Molecular Catalysis A: Chemical, vol. 200, no. 1-2, pp. 279-290, 2003.
[16] O. Bergadà, P. Salagre, Y. Cesteros, F. Medina, and J. E. Sueiras, "High-selective Ni-MgO catalysts for a clean obtention of 2phenylethanol," Applied Catalysis A: General, vol. 272, no. 1-2, pp. 125-132, 2004.

[17] J. G. Smith, "synthetically useful reactions of epoxides," Synthesis, vol. 8, pp. 629-656, 1984.

[18] I. Kirm, F. Medina, J. E. Sueiras, P. Salagre, and Y. Cesteros, "Hydrogenation of styrene oxide in the presence of supported platinum catalysts to produce 2-phenylethanol," Journal of Molecular Catalysis A: Chemical, vol. 261, no. 1, pp. 98-103, 2007.

[19] S. Krishnamurthy, R. M. Schubert, and H. C. Brown, "Hydrogenation of styrene oxide forming 2-phenyl ethanol," Journal of the American Chemical Society, vol. 95, p. 8486, 1973.

[20] A. A. Dabbawala, N. Sudheesh, and H. C. Bajaj, "Palladium supported on chitosan as a recyclable and selective catalyst for the synthesis of 2-phenyl ethanol," Dalton Transactions, vol. 41, no. 10, pp. 2910-2917, 2012.

[21] T. F. Wood and J. Clifton, "Process for preparing beta-phenyl ethyl alcohol," USP 2.524.096, 1950.

[22] I. Kirm, F. Medina, X. Rodríguez, Y. Cesteros, P. Salagre, and J. E. Sueiras, "Preparation of 2-phenylethanol by catalytic selective hydrogenation of styrene oxide using palladium catalysts," Journal of Molecular Catalysis A: Chemical, vol. 239, no. 1-2, pp. 215-221, 2005.

[23] B. D. Cullity, Elements of X-Ray Diffraction, Addison-Wesley, New York, NY, USA, 1978.

[24] L. A. García-Cerda, K. M. Bernal-Ramos, S. M. Montemayor, M. A. Quevedo-López, R. Betancourt-Galindo, and D. BuenoBáques, "Preparation of hcp and fcc $\mathrm{Ni}$ and $\mathrm{Ni} / \mathrm{NiO}$ nanoparticles using a citric acid assisted Pechini-type method," Journal of Nanomaterials, vol. 2011, Article ID 162495, 6 pages, 2011.

[25] T. N. Narayanan, M. M. Shaijumon, P. M. Ajayan, and M. R. Anantharaman, "Synthesis of high coercivity core-shell nanorods based on Nickel and Cobalt and their magnetic properties," Nanoscale Research Letters, vol. 5, no. 1, pp. 164-168, 2010. 

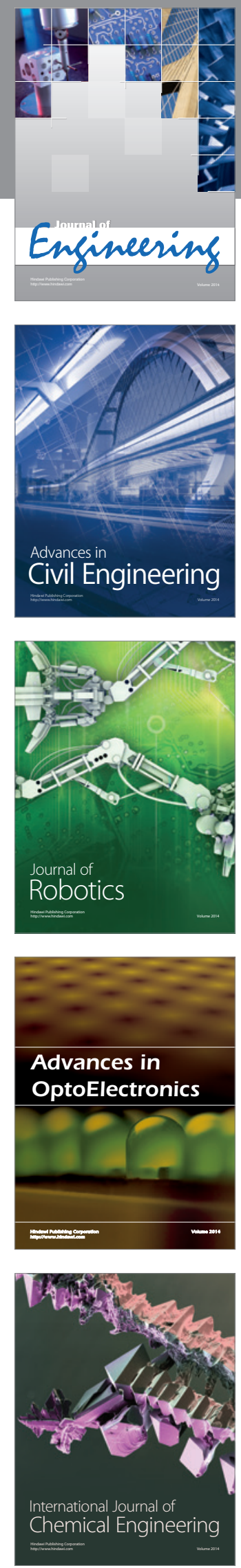

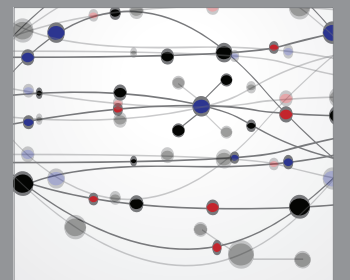

The Scientific World Journal
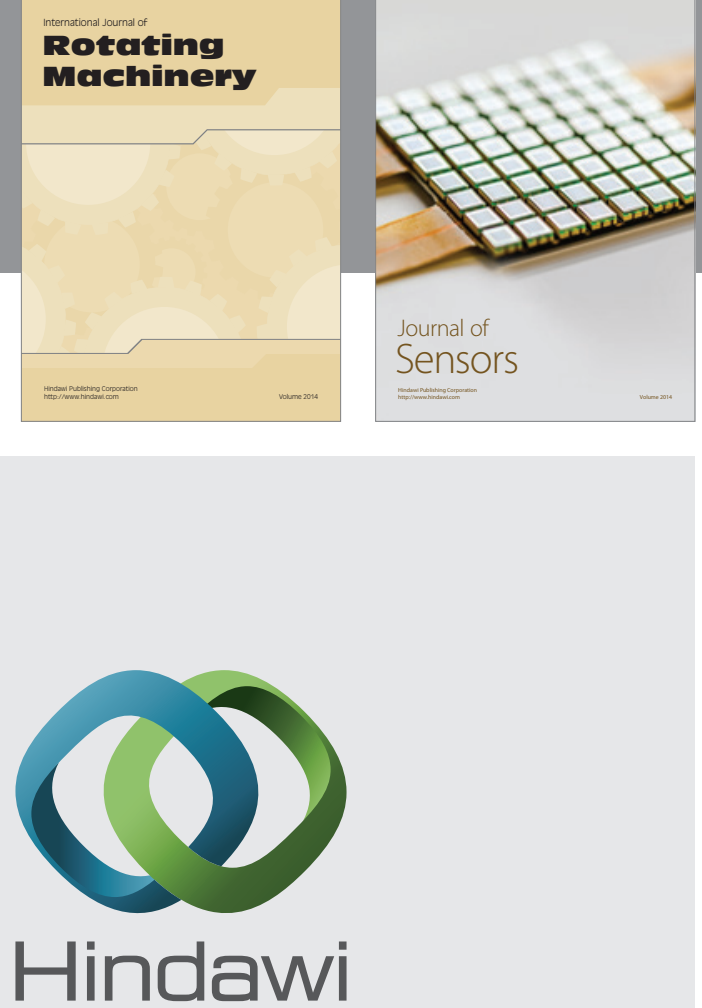

Submit your manuscripts at http://www.hindawi.com
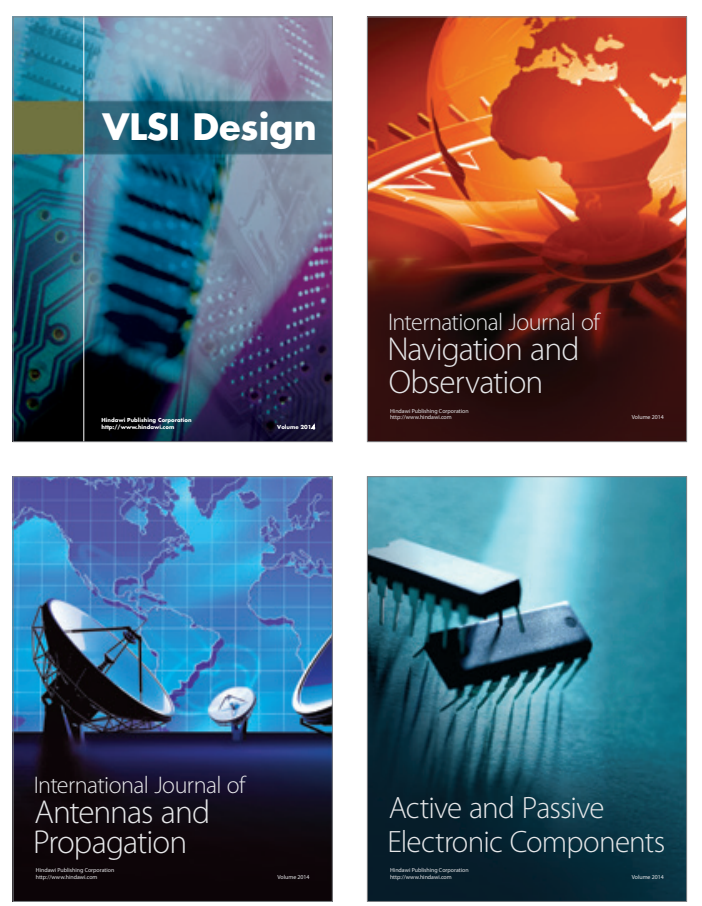
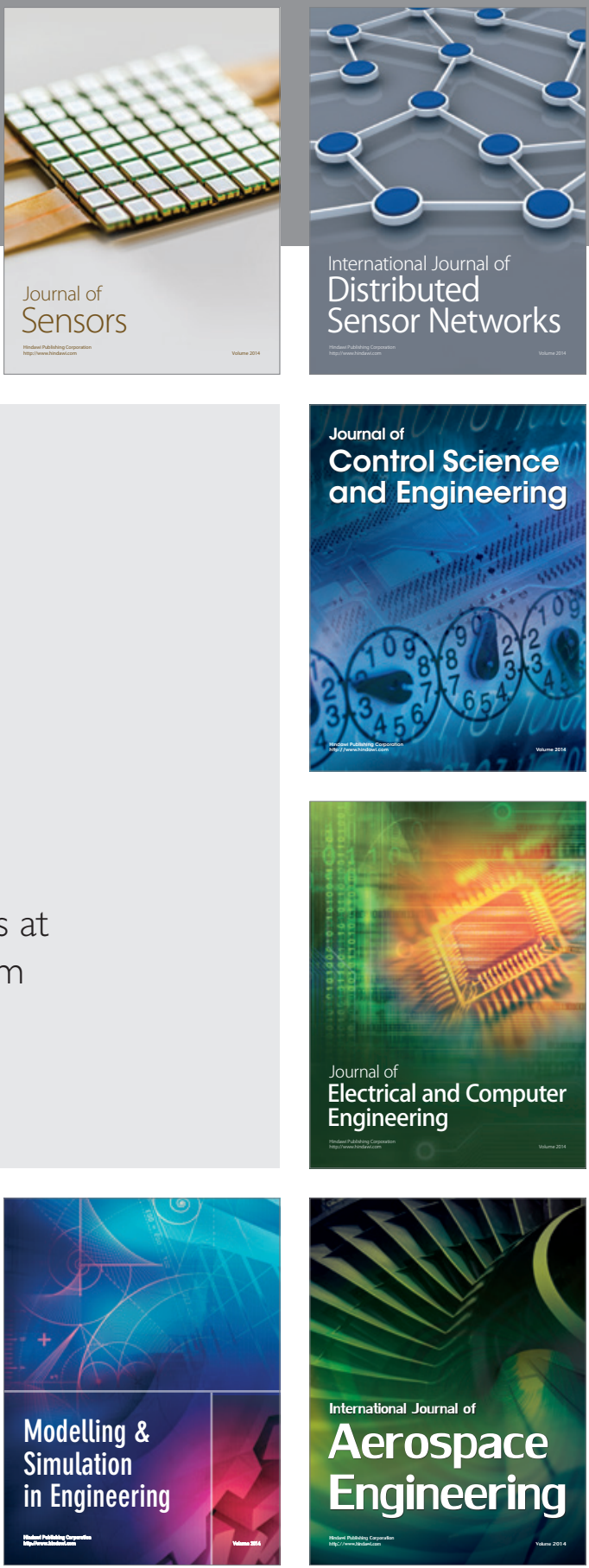

Journal of

Control Science

and Engineering
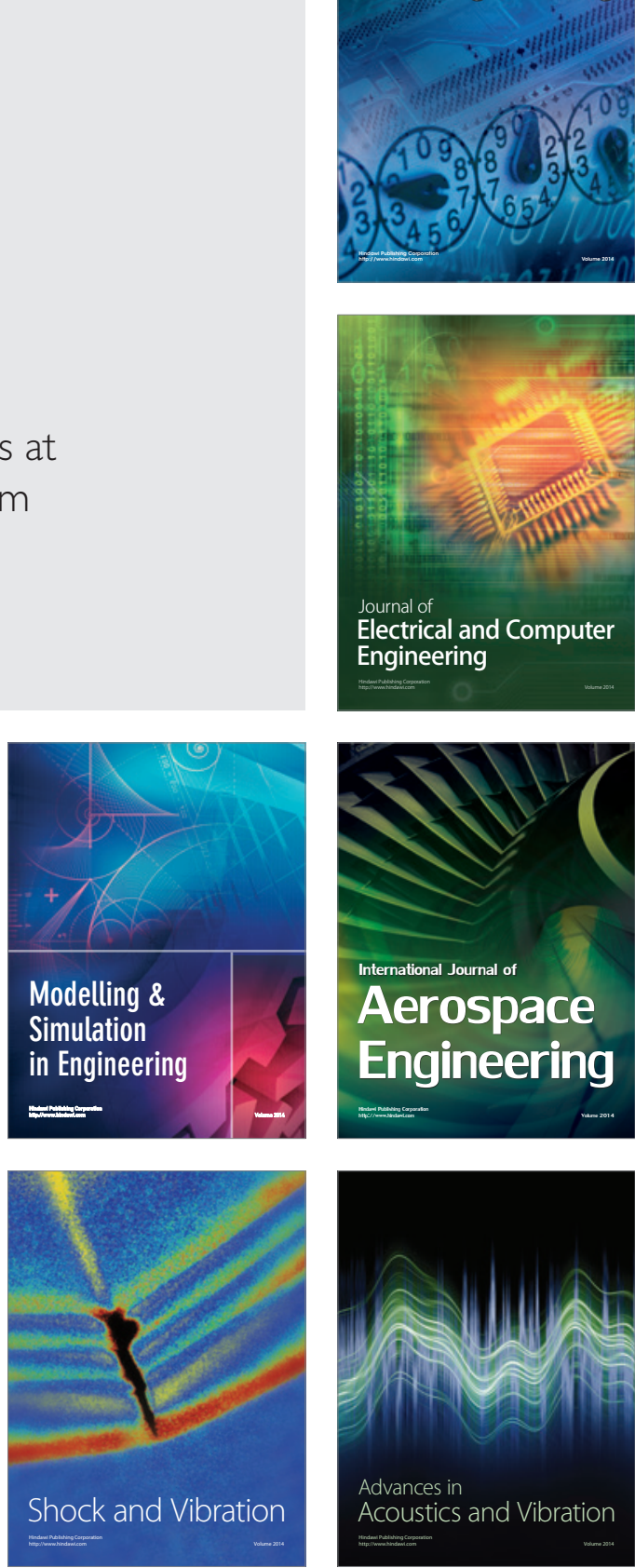